\title{
A IMPORTÂNCIA DA RELAÇÃO PARENTAL NA ESTRUTURAÇÃO DOS PRIMEIROS "ELOS ERÓTICOS LEVES"
}

Maria do Carmo de Andrade Silva ${ }^{1}$

\author{
SEXUALITY AND FAMILY - THE IMPORTANCE \\ OF THE PARENT RELATIONS \\ IN THE FIRST "LIGHT EROTIC LINKS”
}

Resumo: A maioria dos autores segundo Kaplan (1999), acredita que as primeiras experiências sensuais, modelam o desejo sexual e são iniciadas na infância de cada um. Segundo a autora o desejo de contato íntimo e repetido de prazer, que a criança desfruta com seus pais, através de (dormir junto, segurar, abraçar, olhar, acariciar, amamentar, cheirar, beijar, lamber, fazer cócegas, soprar, cantar, rir, banhar, secar, brincar, etc.), comportamentos freqüentes nas interaçôes familiares, e na maioria das vezes, associados à satisfação de necessidades básicas, são considerados estimulantes, "elos eróticos leves”, para as crianças pequenas. E por serem experiências amorosas de prazer, serão internalizadas, nos códigos de memória sensual dos indivíduos. Predispondo a criança, à futuramente desejar objetos, que lhe propicie sensaçōes semelhantes às que teve. Assim, a constituição dos "elos eróticos primários leves", a progressiva aprendizagem discriminativa pela repressão sexual (quando, o que, com quem e onde pode ou não ser realizado), e a experimentação futura de outros relacionamentos afetivos sexuais, propiciarão: reforçamento nos "elos eróticos primários", ou alterações a estes, em função de similaridades ou oposições vivenciadas. Acredita-se, que os circuitos sexuais, acham-se extremamente interligados às partes do cérebro, que analisam as experiências complexas e aos sistemas de armazenamento e recuperação de memória, fazendo com que o desejo e o prazer, sejam fortemente influenciados pelas experiências vivenciais de cada um.

Psicóloga. Mestre em Psicologia e Livre Docente em Sexualidade Humana. Coordenadora do Ambulatório de Sexologia do Instituto de Ginecologia da UFRJ.e-mail: mariacarmoas@yahoo.com.br 
Palavras-chave: Desenvolvimento; elos eróticos leves; relacionamento familiar; mapas de erotismo.

Abstract: According to Kaplan (1999), the majority of the authors believe that the sensorial experiences initiated in the childhood mold the sexual desire. According to the authors the desire of intimate contact from the parents relation (sleeping together, holding hands, hugging, looking, patting, breast feeding, smelling, kissing, liking, ticking, blowing, singing, laughing, bathing, drying, playing etc), are considered " light erotic links" stimulus for the small children because they are related to basic needs. As they are love in pleasure experiences they are kept in the inner sensorial memory. The children are then prone to desire objects causing similar sensations. The primary light erotic links establishment, the progressive discriminating learning from sexual repression (when, what, with whom, sexual activities can or cannot be made), and the future experiences from other affective/ sexual relationship will provide reinforcement or change in the "primary erotic links" as experiences are similar or opposite to the previous ones. Scientists believe that brain sexual circuits are well interlinked to other brain parts that analyze complexes experiences and to the memory recover and storage system causing previous experiences to influence desire and pleasure.

Keywords: Development; light erotic links; family relationship; erotic maps.

Para os atuais estudiosos da Neurociência, referidos por Iversen, Kupfermann, e Kandel, (2003), o prazer é um fator chave no controle dos comportamentos motivados nos seres humanos. Porém, como o prazer é extremamente subjetivo torna-se difícil estudá-lo em animais, fazendo com que os mecanismos neurais aí envolvidos, ainda sejam pouco entendidos. No entanto, observase que mesmo em relação à fome, pessoas são capazes de fazer severas dietas, exclusivamente pelo prazer de se perceberem mais magras e, assim, acreditamse mais aceitas e desejáveis social e sexualmente. Parece que os mecanismos do prazer são sobrepostos, ou mesmo coincidentes, aos mecanismos encefálicos (incluindo aqueles do hipotálamo), envolvidos com as recompensas e o reforço de comportamentos aprendidos. Observando-se que os sistemas neurais envolvidos com o prazer usam uma variedade de agentes neurotransmissores e dentre eles, particularmente a dopamina tem se feito presente, em situações percebidas como prazerosas.

Desde pequenos desfruta-se prazer ou desprazer através dos sentidos, (visão, audição, gustação, olfato, tato) e de fantasias. Além da satisfação de necessi- 
dades básicas: fome, sede, sono, aconchego e higiene, que também levam ao prazer. Assim, desde muito cedo nosso prazer tem relação com o "outro". O prazer, o desprazer, o êxtase, a tristeza, a ansiedade e a raiva são sentimentos - fenômenos que dão cor, paixão e personalidade à nossa vida. São nossas individualidades e começam a se desenvolver e diferenciar-se, desde muito cedo, através de interações do organismo com o meio ambiente que o cerca.

Segundo Gardner e Kendel (2003), as modificaçōes constantes das sinapses durante a vida indicam que todos os comportamentos de um indivíduo, são formados por mecanismos genéticos e ambientais que agem sobre o encéfalo. Isto se dá, desde os comportamentos mais íntimos aos mais públicos. Os eventos do dia-a-dia, assim como as estimulaçôes ou privações sensoriais, podem efetivamente enfraquecer conexōes sinápticas em determinadas circunstâncias ou reforçá-las em outras. Portanto, as vivências aprendidas podem levar a alterações estruturais no encéfalo. Assim, também os mapas da superfície corporal, no córtex somatossensório primário, variam entre indivíduos, de modo a refletir o uso diferencial das vias sensórias. Portanto, as conexões das vias aferentes no córtex podem expandir-se ou retrair-se dependendo das atividades vivenciadas por cada um.

Estas reorganizações das informaçōes aferentes são também enviadas em níveis encefálicos mais inferiores, especificamente aos núcleos da coluna dorsal, que contém as primeiras sinapses do sistema somatossensório, levando a crer, que ocorrem em todas as vias somáticas. Portanto à medida que crescemos e somos expostos a diferentes combinações de estímulos, adquirimos nossa individualidade e identidade específica.

Para estudar os Mecanismos Emocionais e indiretamente os Sentimentos precisamos:

10) Estudar como o estímulo adquire significância emocional (função do processo cognitivo consciente e do processo automático inconsciente);

$2^{\circ}$ ) Como certas respostas autonômicas e esqueleto motoras, são desencadeadas uma vez adquirindo significado emocional;

3o) Identificar os circuitos no córtex cerebral, responsáveis pelos sentimentos;

$\left.4^{\circ}\right)$ Estudar, como os estados emocionais e sentimentos, interagem como retro alimentação dos sistemas periféricos autonômicos e esqueleto motores, para que o córtex cerebral modele a experiência emocional.

Quando ocorre a evidência de uma sensação física, chama-se a isso emoção física. E quando se toma consciência desta sensação física, então se denomina 
esta percepção de sentimento. Como por exemplo: sente-se que o coração bate forte, isso é uma emoção física. Porém, esta emoção poderá ser conscientemente percebida como: um sentimento de medo ou um sentimento de paixão - tudo dependerá dos ingredientes envolvidos, para que um ou outro tipo de percepção ocorra.

Segundo Iversen, Kupfermann e Kendal (2003), as experiências de medo, raiva, prazer e felicidade são reflexos de uma intercomunicação entre centros encefálicos superiores e regiões subcorticais, como o hipotálamo e a amídala. Assim estímulos prazerosos e nocivos têm efeitos duplos. Primeiro eles desencadeiam respostas autonômicas e endócrinas (integradas por estruturas subcorticais), que preparam o indivíduo para o ataque, luta, sexo ou fuga e, um segundo grupo desse mecanismo, envolve o córtex cerebral. Quando o processamento cortical de estímulos emocionalmente significantes transformase em uma experiência consciente de emoção (sentimento), transmitem sinais para centros inferiores, o que pode aumentar ou diminuir as manifestações somáticas das emoções.

Com isso pode-se perceber, que muitas das respostas emocionais primárias são aprendidas e, durante essas vivências, a retro alimentação visceral tem uma importante função. Mas, com o desenvolvimento e a vivência de diferentes experiências, passa-se a depender muito da cognição, processo utilizado para avaliar o meio ambiente, fazendo com que as sensaçóes viscerais, tornem-se menos importantes. As conexões da amídala com os córtices associativo temporal (giro do cíngulo) e frontal (pré-frontal), fornecem os meios pelos quais as sensações viscerais desencadeiam as várias associaçōes, o que irá constituir a interpretação cognitiva dos estados emocionais.

O ser humano ao nascer encontra-se completamente dependente de cuidados essenciais, sendo na maioria das vezes, através das relaçóes parentais, que poderá satisfazer suas necessidades básicas e sentir prazer por isso. Permeando esses momentos de cuidados, outras tantas interaçōes afetivas e sensuais fazemse presentes. Dentre estas, as trocas de olhares, os sorrisos, os sons, os cheiros, o acariciamento, as fantasias e projeções de realização de desejos e obtenção de prazer. Constituindo-se assim, através desses contatos, o início do desenvolvimento das trocas afetivas, sensuais e de realização de desejos, portanto obtenção de prazer, constantemente associado a elas. Trocas iniciadas na família, mas que irão progressivamente crescendo em quantidade e variabilidade, através das diversas interações com o mundo. Processo que caracteriza o desenvolvimento humano e estrutura, a forma de ser e de sentir-se, enquanto ser de relações, Andrade-Silva (1999). 
A maioria dos autores segundo Kaplan (1999), acredita que as primeiras experiências sensuais, modelam o desejo sexual e são iniciadas na infância de cada um. Pode-se especular segundo esta autora, que o desejo de contato emocional e físico íntimo, contínuo e repetido de prazer mútuo, que a criança pequena desfruta com seus pais e familiares, através de: (dormir junto, segurar, abraçar, olhar, acariciar, amamentar, cheirar, beijar, lamber, fazer cócegas, soprar, cantar, rir, banhar, secar, brincar, etc.), comportamentos freqüentes nas interações em várias famílias, são considerados estimulantes "eróticos leves", para as crianças pequenas. Atividades que produzem prazer sensual, tanto para os pais como para os filhos, constituindo-se em uma percepção de prazer, pela simples existência da vivência do momento entre eles.

Por serem estas experiências amorosas contínuas e de prazer, normalmente serão assimiladas e internalizadas, nos códigos de memória sensual dos indivíduos desta forma estimulados. Predispondo a criança, a futuramente desejar objetos, que lhe propicie sensações semelhantes às que teve com esses jogos, atividades que caracterizaram seu início de contato íntimo com o "outro", processos que se estruturaram associados ao seu "mapa erótico" inicial. Onde nuances do sentir, especialmente através: do olhar, do toque, do cheiro, do gosto, dos sons e do que se imaginou; foram adquirindo significados próprios, através da vivência de cada um.

Posteriormente, pelo contato com outras interaçōes emocionais significantes e, da percepção das exigências ideológicas do grupo social à que se pertence, irão se estruturando outras tantas sensações, crenças e atitudes em relação à sensualidade e à sexualidade. Mais especificamente, quanto às permissividades e restrições, relativas às manifestaçōes dos desejos sexuais. Quando novas sensações de prazer e desprazer irão sendo internalizadas, organizandose outros grupos de sentimentos.

Portanto, a constituição dos “elos eróticos primários leves”, a progressiva aprendizagem discriminativa (quando, o que, com quem e onde pode ou não ser realizado), assim como, a experimentação futura de outros relacionamentos afetivos sexuais, propiciarão: reforçamento nos "elos eróticos primários leves", ou promoverão acréscimos ou alterações a estes, em função de similaridades ou oposições vivenciadas. Assim, em alguns casos, por incompatibilidade nas experiências, algumas pessoas apresentam-se ambivalentes entre: o prazer, a culpa ou mesmo o desprazer. Processo que as leva a uma série de conflitos. Acredita-se, que os circuitos sexuais, acham-se extremamente interligados às partes do cérebro, que analisam as experiências complexas e aos sistemas 
de armazenamento e recuperação de memória, fazendo com que o desejo e o prazer, sejam fortemente influenciados pelas experiências vivenciais de cada um.

Dentre as necessidades humanas, as relações sexuais, e toda a sensualidade e sexualidade que as constituem, caracterizam-se como um novo elo de possibilidade de constituição de vínculos afetivos semelhantes aos iniciais. Elos que podem propiciar novamente, as boas sensações de intimidade, carinho, segurança, aconchego e prazer, que vivenciaram em suas relações parentais iniciais. Enfim, um grande sonho de alcançar a possibilidade de superar a angústia da solidão e encontrar sintonia e prazer, através da expansão amorosa e união autêntica e segura com o "outro."

Sabe-se que a comunicação não verbal intensifica e auxilia as interações humanas. Os sinais não verbais de expressão humana foram, sem dúvida, a base fundamental de todo processo interativo inicial (mãe x bebê). Momentos relacionais, onde a necessidade de entender o "outro", que não sabia dizer o que desejava, o que lhe satisfizesse ou incomodasse, tornava-se o objeto primordial e essencial da relação. Uma interação, que só poderia ser satisfatória, se realmente se desse através de um processo intenso de tentativas de identificação, com os estados emocionais desejantes do "outro".

Acredita-se que, a intensidade desses momentos não verbais de comunicação inicial, deixe marcas profundas e significantes em todo nosso processo de interação, especialmente no que se refere, às necessidades afetivo-sexuais de cada um. Pois são expressões fortes e, que de forma inequívoca, apresentamse e manifestam-se, nas percepções das comunicações não verbais do indivíduo adulto. Expressões, que muitas vezes, complementam de forma nítida as comunicaçōes verbais. Ou ao contrário, denunciam contradiçōes, entre o que está sendo expresso verbalmente e o que é percebido emocionalmente, fazendo com que a dúvida, quanto ao que está sendo verbalizado, seja a tônica. Pois, a percepção do "relato" não verbalizado, é muito mais forte para quem percebe.

Muitas vezes, os desejos sexuais são denunciados pela direção ou a qualidade do olhar, pelas expressões faciais, os tons de voz, ou as direções das posturas físicas. Apontam para o fato, de que: o arsenal de muniçōes da comunicação não verbal, apesar de sofrer muitas interferências de conteúdos racionais, não é de fácil submissão ou controle intelectivo. Tenta sobrepujá-los e escapar, lançando mão de nuances não verbais, de detalhes primitivos das interações iniciais, dando-se a perceber ao "outro", especialmente, quando por algum motivo, consciente ou inconsciente, não pode ser completamente manifesto. 
Da mesma forma, que se fazia entender, nas interações não verbais primordiais, do processo de interação e desenvolvimento do bebê com sua mãe.

O que é considerado atraente para cada um, encontra-se fortemente associado às expectativas, admirações, obstáculos, afetos, lutas e ansiedades, Alferes (1993). Situaçôes significantes para cada pessoa e, que de forma específica, encontram-se entrelaçadas, aos desarrumados sentimentos ambivalentes, tão pessoais e próprios à existência humana.

O desejo e o prazer, por suas próprias naturezas são complexos e, é dessa riqueza de complexidades, que surgem as atrações, as paixões, as necessidades de unir-se e satisfazer-se com o “outro”. O desejo sexual não é algo palpável, não é tão "arrumadinho" como muitas vezes se gostaria que fosse. Pois sendo uma pulsão de vida, de energia, de união e expansão e de satisfação de necessidade intrínseca à estrutura de personalidade de cada desejante, pode ser ativado pela forma como o outro é imaginado e fantasiado, na percepção de quem deseja e, muitas vezes, não representa conexão lógica com a realidade do que é o "outro".

O erotismo é um processo multifacetado, através do qual, nossa capacidade inata para a "tesão" foi moldada, suprimida ou supervalorizada, estruturandose assim, o desejo de cada um. A moldagem erótica, ou a forma como se constituirão os conteúdos desejados, se fará através de: mensagens claras ou sutis, verbais ou não verbais, conscientes ou inconscientes, mas que têm conexões com as vivências afetivo-sexuais de cada um. Assim, o resultado de tudo isso irá esculpir a forma, a intensidade, os objetos, as situações e as possibilidades de manifestação do desejo (latente, fantasiado, expresso ou executado) de cada um.

Numa tentativa de entender como e porque as formas de expressão da sexualidade podem assumir contornos tão divergentes dos valores "oficiais", John Money (1986) propôs um conceito geral de lovemaps (ou mapas de amor), uma representação personalizada do desenvolvimento ou uma matriz na mente e no cérebro, que representa o (a) amante idealizado (a) e o programa ideal de atividade sexo-erótica com tal amante.

De acordo com a idéia de Money (1986), cada pessoa traria em si uma espécie de projeto sexual idealizado, construído primariamente a partir do primeiro casal com que se tem contato - os pais. Daí em diante, a dinâmica dos relacionamentos acrescentaria os detalhes, que irão compondo o quadro final desse mapa de amor personalizado. Tais mapas podem ser distorcidos (ou vandalizados, no dizer do autor) na medida em que a repressão às formas 
naturais de expressão da sexualidade deixe pouca alternativa, para a subsistência do impulso sexual. Impossibilitado de se expressar, o impulso sexual buscaria os caminhos que restassem. Especialmente aqueles mais "esquecidos" pela repressão, o que redundaria em formas menos "usuais" de expressão sexual.

Assim, Money (1986) nos diz: que um mapa de amor que não é normofílico, pode ser classificado como: hipofílico, significando ser incompleto ou insuficiente; hiperfílico, quando é muito dominante ou prevalente; e parafílico, uma forma peculiar e divergente de uma dada norma.

Essa descrição geral sustenta o conceito clássico de que a repressão age como base das parafilias, mas não é por simples efeito de compressão, que poderia se tornar explosivo, mas também por distorção, desse projeto sexo erótico idealizado a que ele chamou de "mapa de amor". A vandalização dos mapas de amor mantendo, por exemplo, a violência e a dor como escape das sensações sexo eróticas, responderia pelo valor excitatório que essas formas passariam a ter, na fantasia ou na prática de vida.

Outra chave para a compreensão deste processo está no perfil de apaixonamento. Ressalta o autor, que esse apaixonamento é uma forma de evidência dos mapas de amor, em grande parte até então inconscientes. A partir da adolescência, e provavelmente sob a ação dos hormônios sexuais, os mapas de amor dormentes por baixo dos níveis conscientes de atividade, são despertados pelo surgimento de uma pessoa que, repentinamente, "preenche" o espaço e se torna a representação personificada do desejo. Não se "escolhe" o objeto da paixão, ressalta ele, esse objeto surge e se impõe nos sonhos, nas fantasias e talvez nas práticas do sexo, e será tão mais "exótico", quanto mais vandalizado tenha sido o mapa de amor. Uma vez que os impulsos sexuais lutam para subsistir aos limites que lhes sejam impostos.

Entretanto, resta ainda uma questão fundamental que permanece em aberto: a absoluta predominância dos desvios sexuais na população masculina. Em princípio, isso indica mesmo, que há algo mais em pauta do que a simples questão da repressão sexual, até porque, seria fácil encontrar evidências de que essa repressão se faz mais fortemente sobre as mulheres do que sobre os homens. Assim sendo, o que a realidade mostra (predominância de desvios em homens) parece ser o oposto do que a teoria poderia prever dada a maior repressão, em mulheres.

As primeiras evidências de que isso é possível aparecem também no início do século XX. E nesse sentido, Freud (1931-1973) menciona que não havia 
dúvida de que a bissexualidade presente, conforme acreditamos, na disposição inata dos seres humanos, apresenta-se mais claramente nas mulheres do que nos homens.

Mas afinal, por que essa disposição para a bissexualidade tem maior expressão nas mulheres? E qual seria a relação entre essa disposição e a formação dos desvios sexuais, mais freqüentes nos homens?

A costura teórica entre esses princípios com os trabalhos de Money (19861988), sobre o desenvolvimento da identidade sexual nos traz melhores possibilidades de compreensão do conjunto.

A partir de um núcleo de "sexo-afeto" não diferenciado, a moldagem da personalidade masculina ou feminina se faz em passos sucessivos. $O$ primeiro seria a imposição de uma norma social, como regras e valores culturais, que, como assinalam Freud (1931-1973) e Reich (1927-1974) colocamse na base do conflito entre o "eu instintual" e o mundo exterior. Aqui se define o que é "certo" ou "errado" no comportamento sexual, o que se pode ou não se pode fazer, e o que se deve ou não se deve sentir.

O modo de imposição dessa norma é visto, na ação sócio-familiar por dois mecanismos básicos: o primeiro é a rejeição, seja ela direta ou indireta. Se a criança não segue o padrão moral da família, retiram-se dela o afeto, as pessoas lhe voltam as costas, ela é posta de castigo, os pais silenciam e lhe negam até o sorriso. Não é de forma alguma necessário que se pense no castigo físico. A grande forma de repressão é a privação do afeto e do convívio social. A criança é marginalizada, até que se desculpe e prometa seguir a norma no futuro. O mesmo ocorrerá, mais tarde, no grupo social, onde o "diferente" é discriminado e marginalizado, por não acatar o perfil sóciosexual do grupo. O segundo mecanismo de moldagem ou de imposição da norma é a humilhação, forma mais perversa de retirada do afeto, à qual se acrescenta o sentimento do ridículo e da execração pública.

Na mesma medida em que essa moldagem sócio-familiar se faz introjetada, a imposição da norma, agora assumida como valor pessoal, transforma-se numa imposição de culpa, como sentimento resultante da transgressão praticada ou simplesmente imaginada. A antecipação da reação dos pais ou da comunidade, à transgressão cometida resulta enfim, numa nova imposição, a imposição do silêncio. Se não é possível evitar a fantasia (ou, quem sabe, o ato de transgressão sexual em si), ao menos se deve manter o segredo, o que evita a rejeição e humilhação.

Atividades sexuais comuns, como as resultantes da exploração do próprio corpo na masturbação (única forma de exploração do corpo à que se dá nome, 
para melhor reprimir) ou a exploração do corpo de parceiros, como no clássico "brincar de médico", refletem desde cedo a tendência do impulso sexual, para subsistir e se fazer presente, em que pese a repressão que se faça sobre ele.

Os sinais de que uma criança incorporou a norma e aceitou a imposição do silêncio, evidenciam-se no segredo com que praticam essas atividades sexoeróticas, desfrutadas e repetidas; mas jamais comentadas com os pais. E quando esse tipo de transgressão acontece, ao contrário do que diriam os manuais moralizadores, o perfil sexo erótico permanece nos limites da "anormalidade aceitável". O risco maior é que, nem mesmo essas formas "secretas", mas "normais" de expressão da sexualidade sejam deixadas em aberto. Restarão, talvez, apenas caminhos obscuros e tortuosos. Meandros pelos quais a sexualidade vai se escoar, marcando uma forma de desejo ou de associação sexual anômala. A vandalização, enfim, resulta da repressão sem escape.

O segredo imposto, agora assumido como necessidade pessoal de "privacidade" ou qualquer outro nome que se dê, persiste como uma forma de "ter sexo", quando apenas aparentemente a criança ou o jovem não o tem. Do mesmo modo, a cumplicidade sexual que se estabelece, nos tantos jogos de "casinha", isola os pais e professores (representantes da norma social imposta), do mundo da sexualidade infantil.

Fez-se afinal uma verdadeira clivagem, uma separação artificialmente induzida entre a expressão direta do sexo e a expressão purificada do afeto. A primeira só cabe no espaço do secreto, do escondido, da cumplicidade (se isso puder ser conseguido) com parceiros igualmente "culpados". A segunda, a suave expressão de carinho, assexuado, é reservada aos pais, irmãos e aos demais níveis de relação onde seria considerada: incestuosa, imoral ou inconveniente. Claro fica que, quanto mais restritiva a condição de cumplicidade sexual, maior a dificuldade de ajuste com parceiros variados.

Feita essa dicotomia essencial entre afeto e sexo (o que nos aproxima bastante do que se possa chamar de "resolução edipiana"), restam valores separados, do amor familiar purificado e do erotismo sujo e marginal. Estão agora postas as bases, para que pessoas normais em sua vida familiar apresentem desejos ou práticas parafílicas no que tange à sexualidade.

Mas a questão que Money (1986), desencadeia não para nesse nível. Ele prosseguiu em 1988, para tentar elaborar o que chamou de estratagemas que visam à manutenção da sexualidade. Esses seriam caminhos alternativos usuais, não atingidos ou até estimulados pela própria atividade repressora anterior ao ponto de clivagem. 
O grupo desses estratagemas seria a drástica redução da sexualidade, às vezes ao nível da total supressão da consciência (o que é bem mais freqüente nas mulheres), enquanto que o segundo mantém formas vivas de sexualidade, mas conduzidas por formas parafílicas. Em outras palavras, diante da pressão anti-sexual imposta pelo meio sócio-familiar, restam dois caminhos mais comuns: a hipofilia ou a parafilia. Como já vimos, se existe um certo grau, socialmente controlável, a parafilia pode receber o nome mais comportado de normofilia.

É evidente, que não há certeza do porque, o desvio parafílico é mais freqüente nos homens, ao passo que, o desvio hipofílico é mais comum nas mulheres DSM-IV (2002).

Para Kaplan (1999), pessoas que desenvolvem desejos sexuais "normais", geralmente não se lembram de incidentes que tenham relação com suas práticas sexuais. Enquanto aquelas que possuem desejos incomuns ou parafilícos, geralmente de forma espontânea ou através de processo terapêutico, recordamse de incidentes que as vincularam nestes modelos. Quando situações inadequadas, negativas, dolorosas ou violentas, constituem as primeiras experiências eróticas da criança, este processo pode resultar em relações de medo ou desejos atípicos e, até mesmo patológicos no adulto.

Às vezes, segundo Kaplan (1983) e Money (1988), em alguns casos, crianças erotizam experiências negativas dolorosas e as transformam, em desejos sexuais quando adultas. Em outras palavras, crianças que vivenciam surras significantes, ou desprezos intensos, podem desenvolver desejos de punição física para si próprias ou para seus amantes durante uma relação sexual adulta.

Kaplan (1999), após mais de 7.000 avaliações sexuais que conduziu em seus últimos 20 anos de trabalho clínico, relatou não ter encontrado, um só paciente com fantasias e desejos sádicos ou masoquistas, que não tivessem experienciado, atos cruéis enquanto crianças. Às vezes, a relação é direta e clara, em outros, a conexão entre o trauma infantil e um desejo incomum apresenta-se simbolicamente representado. Assim, um menino que se relacionou com uma mãe cruel e que o rejeitava emocionalmente, pode vir a desenvolver o desejo: de ser agredido ou de agredir física ou emocionalmente a si mesmo, ou à sua parceira, quando adulto.

Contudo, as dores físicas e/ou emocionais, assim como as imagens mentais negativas (que evocam emoções de risco e perigo), podem se superpor ao 
impulso erótico, reprimindo-o e/ou anulando-o completamente, como no caso de desejo sexual hipofílico, Kaplan (1999) e Masters, johnson e Kolodny (1997).

Esses perigos não necessariamente são reais, porém são representações simbólicas de medos e ansiedades imaginárias sobre sexo, afeto e/ou intimidade. Sentimentos que se desenvolveram em função das relações interpessoais significantes, especialmente na infância.

Dessa forma, se contabilizarmos os dados que temos até aqui, teremos o primeiro bloco de respostas no próprio texto de Freud de (1931-1973), mencionado anteriormente, em que afirma mais nítida bissexualidade nas mulheres. E, em outra passagem do mesmo trabalho, se estende sobre o que pode explicar a diferença do quadro hipofilia / parafilia entre homens e mulheres. Sinaliza, sistematizando seu ponto de vista quanto à progressão edipiana um ponto crucial que diferencia o processo de clivagem sexo afeto para meninos ou meninas. Para ele, o objeto inicial (a mãe) deve ser totalmente substituído no campo sexual, retendo apenas o conteúdo afetivo, já cuidadosamente "destilado". Para ela, o objeto inicial (a mãe) pode permanecer menos criticamente assexualizado, enquanto um novo objeto de amor assexuado (o pai) se instala. É possível, que essa mudança de objeto em meio ao processo de desenvolvimento permita a ela, maior espaço desde o princípio, para a manutenção da bissexualidade inicial, ao passo que para ele, a clivagem tenha que ser mais radical e mais intensa, Freud (1931- 1973).

De qualquer modo, não se pode ignorar que a sociedade historicamente se preocupa também em impor normas anti-sexuais para ambos, meninos e meninas, mas deixa para eles (mais do que para elas) os escapes do "sexo de rua", desde logo definido como marginal.

Essa mesma clivagem sexo-afeto, então, em linhas gerais, pode ser reduzida ao binômio "afeto familiar x sexo marginal", onde a marginalização do sexo reflete a luta da sexualidade para subsistir em que pese o rigor da repressão. Nesse sentido, a constituição de um desvio parafílico seria a conseqüência de mapas de amor vandalizados. Dessa forma, como propôs John Money (1988): A parafilia representa o estratagema de desenvolvimento utilizado, para salvar o erótico e sexual, da total erradicação nos mapas de amor, mas ao custo de uma clivagem entre desejo e amor.

\section{Como aponta o DSM IV:}

[...] O diagnóstico de parafilias entre as várias culturas ou religiões é complicado pelo fato de que aquilo que é considerado um desvio em um contexto cultural pode ser mais aceitável em outro (DSM IV, 2002, pp.540). 


\section{Refeferências bibliografica}

ALFERES, V.R. Atração interpessoal, sexualidade e relações íntimas em psicologia social. In: VALA, J. \& MONTEIRO, M. B. (Org.). Psicologia Social. Lisboa: Fundação Calouste Gultbenkian, 1993

ANDRADE SILVA, M.C. Formação e desenvolvimento da identidade sexual ou identidade de gênero. In: MARCOS RIBEIRO (org.). O Prazer e o Pensar. São Paulo: Gente, 1999.

DSM-IV-TR. (2002). Manual Diagnóstico e Estatístico de Transtornos Mentais. Porto Alegre: Artimed, 2002.

FREUD, S. (1931). Obras completas. Madrid: Biblioteca Nueva, 1973. GARDNER, E.P. \& KANDEL, E.R. Tato. In: KANDEL, E.R. SCHWARTZ, J.H. \& JESSELL, T.M. (Eds). Princípios da Neurociência. São Paulo: Manole, 2003.

IVERSEN.S.; KUPFERMANN, I. \& KANDEL, E.R. Sentimentos e Emoçōes. In: KANDEL, E.R.; SCHWARTZ, J.H. \& JESSELL, T.M. (Eds.). Princípios da Neurociência. São Paulo: Manole, 2003.

KAPLAN, H.S. The evaluation of sexual disorders: Psychological and Medical Aspects. New York: Brunner Mazel Publishers, 1983. Transtornos do desejo sexual. Porto Alegre: Artimed., 1999.

MONEY, J. Love Maps. Nova York: Irvington, 1986.

MONEY, J. \& LAMACZ, M. Vandalized Love Maps: Paraphilic Outcome of Seven Cases in Pediatric Sexology. New York: Prometheus Books, 1988. REICH, W. (1927). Psicopatologia e Sociologia da Vida Sexual. São Paulo: Global, 1974. 